\title{
Hypodense eosinophil number relates to clinical severity, airway hyperresponsiveness and response to inhaled corticosteroids in asthmatic subjects
}

\author{
H-P. Kuo, T-R. Yu, C-T. Yu
}

Hypodense eosinophil number relates to clinical severity, airway hyperresponsiveness and response to inhaled corticosteroids in asthmatic subjects. H-P. Kuo, T-R. Yu, C-T. Yu. CERS Journals Ltd 1994.

ABSTRACT: The phenotypically distinct low-density eosinophil, with its greater inflammatory potential, is increased in asthma. However, the role of hypodense eosinophils in the development of asthma is still unclear.

We conducted a double-blind, placebo-controlled study to examine the effect of inhaled corticosteroids on the number of hypodense eosinophils in 27 asthmatic subjects and its relationship with clinical severity. The density profile of eosinophils in the peripheral blood was determined using Percoll density gradient fractionation.

Eosinophils recovered from asthmatics were mainly in the lower density fractions $\left(<1.095 \mathrm{~g} \cdot \mathrm{ml}^{-1}\right)(63 \pm 3 \% ; \mathrm{n}=27)$, significantly different from those of normal subjects $(27 \pm 2 \% ; n=7)$. The proportion of hypodense eosinophils was inversely related to the provocative concentration of methacholine producing a $20 \%$ fall in forced expiratory volume in one second $\left(\mathrm{PC}_{20}\right)$ value $(\mathrm{r}=-\mathbf{0 . 7 5})$. Patients with mild asthma had a lower percentage of hypodense eosinophils $(45 \pm 4 \% ; n=14)$ than those with moderate asthma $(67 \pm 3 \% ; n=13)$. Inhalation of budesonide $\left(800 \mu g \cdot\right.$ day $\left.^{-1}\right)(n=15)$ for 4 weeks, but not placebo, significantly improved the $\mathrm{PC}_{20}$ values by 0.97 doubling dose, forced expiratory volume in one second $\left(\mathrm{FEV}_{1}\right) \%$ predicted by $17 \%$, and peak expiratory flow rate (PEFR) by $15 \%$, and decreased PEFR diurnal variability by $5.4 \%$. The percentage of hypodense eosinophils was significantly decreased from $68 \pm 4$ to $47 \pm 4 \%$ in the budesonide group $(n=15)$, but not in the placebo group $(n=12)(63 \pm 4$ to $65 \pm 4 \%)$. The percentage of lower density eosinophils $(1.080-1.085$ and 1.085-1.090 $\left.\mathrm{g} \cdot \mathrm{ml}^{-1}\right)$ significantly decreased in the budesonide group but not in the placebo group, with a concomitant increase in the highest density $(1.095-1.100$ $\mathbf{g} \cdot \mathbf{m l} \mathbf{l}^{-1}$.

We conclude that hypodense eosinophils are closely related to clinical severity and airway hyperresponsiveness. The clinical efficacy of corticosteroids might be mediated by inhibiting the conversion of eosinophils into hypodense subpopulations. Eur Respir J., 1994, 7, 1452-1459.

Dept of Thoracic Medicine, Chang-Gung Memorial Hospital, Taipei, Taiwan.

Correspondence: H-P. Kuo

Dept of Thoracic Medicine

Chang-Gung Memorial Hospital

199 Tun-Hwa N Rd

Taipei

Taiwan

Keywords: Airway hyperresponsiveness airway inflammation

bronchial asthma

corticosteroid

eosinophil

fractionation

Received: December 61993

Accepted after revision April 131994
Airway inflammation is an important factor in the development and perpetuation of bronchial hyperresponsiveness in bronchial asthma [1]. Among several inflammatory cells recruited in airway inflammation, eosinophils predominate [2]. Eosinophil infiltration and the mediators released have been shown to denude airway epithelium [3], and increase vascular permeability, inducing airway oedema [4] and enhancing airway inflammation, which are characteristics of bronchial asthma. The close relationship between the severity of asthma and presence of eosinophils either in peripheral blood or in bronchoalveolar lavage has been explored previously $[5,6]$. Several studies have also demonstrated that quantitation of eosinophil activation, degranulation or cell density are more precise indicators of eosinophil-mediated inflammation than is simply the presence of eosinophils [6-8].
Recently, studies using density gradient fractionation have demonstrated that eosinophils are a heterogeneous population, with functional heterogeneity among subpopulations $[9,10]$. The functionally distinct eosinophil subpopulations may play a different role in the development of airway dysfunction. The phenotypically distinct low-density eosinophil, with its greater inflammatory potential, is increased in asthma [11]. The importance of hypodense eosinophils has been demonstrated in antigeninduced late phase asthma [8], and nocturnal asthma [12], and may reflect the eosinophil subpopulation most likely to cause altered airway function [8]. This particular subpopulation of eosinophils is well-equipped to cause tissue injury, and therefore may be an important participant in the development of airway inflammation. Glucocorticoids form the mainstay of treatment of asthma, and have 
been shown to reduce the degree of airway inflammation and symptoms in asthma [13], as well as nonspecific bronchial hyperresponsiveness [14, 15]. If hypodense eosinophils are involved in the airway inflammation, change in the hypodense subpopulation of eosinophils may parallel the clinical responses to corticosteroids. In this study, we first examined the role of hypodense eosinophils in bronchial asthma by evaluating the relationship of peripheral blood hypodense eosinophils to airway hyperresponsiveness and the severity of asthma. We further investigated whether maintenance treatment with an inhaled corticosteroid, budesonide, had an effect on the magnitude of increased hypodense eosinophils in asthmatics and its relationship with clinical response.

\section{Materials and methods}

\section{Subjects}

Thirty two patients with mild to moderate asthma were enrolled in this study. They comprised 19 men and 13 women, ranging in age from 18-64 yrs, with a mean age of $40 \mathrm{yrs}$. All patients had documented asthma according to American Thoracic Society definition [16], and demonstrated at least $15 \%$ reversibility to their airway obstruction to a metered-dose $\beta$-adrenergic agonist. No subjects took oral or inhaled corticosteroids or other antiinflammatory agents for at least 6 weeks before enrolment.

The severity of asthma was determined on the grounds of clinical features before treatment (frequency of exacerbation and nocturnal attack), peak expiratory flow rate (PEFR) and its variability [17] recorded 4 weeks before study. In brief, "mild" asthmatic patients are those with clinical features of intermittent, brief symptoms less than 1-2 times a week, and nocturnal asthma symptoms less than 2 times a month, as well as PEFR $>80 \%$ predicted at baseline, with variability $<20 \%$. "Moderate" asthma patients are those with clinical exacerbation more than 1-2 times a week, nocturnal asthma symptoms more than 2 times a month, and symptoms requiring inhaled $\beta$ agonist almost daily, as well as PEFR $60-80 \%$ predicted at baseline, but normal after bronchodilator, and with variability $20-30 \%$.

All patients had a normal chest X-ray, with no radiographic evidence of bronchiectasis or allergic bronchopulmonary aspergillosis. All patients had positive skin tests for at least two common allergens, including housedust mite. Patients who currently smoked or who had smoked more than 5 pack-years were excluded, as were those with any past or current diseases, other than asthma, that might have resulted in alteration of lung function. Patients with acute infection within 2 weeks before or during the course of study were excluded. Seven healthy control subjects comprised 3 men and 4 women, ranging in age from 26-58 yrs, with a mean age of 38 yrs. No subject was taking medications or had a history of allergic rhinitis or asthma, positive immediate intradermal skin tests to extracts of housedust, grass, ragweed, trees and animal dander.

\section{Study design}

At a preliminary visit after initial recruitment, all subjects were assessed for suitability, and written consent was obtained after full explanation (selection period). Baseline spirometry and PEFR were measured. In a double-blind design, the asthmatic patients were randomly allocated to two parallel groups. Before entering the study, the patients discontinued their usual maintenance treatment for at least 3 weeks. During this period, no patient experienced serious asthma attacks requiring medications more than inhaled $\beta$-agonists. Sixteen patients were treated with inhaled budesonide (Turbuhaler, Astra, Sweden), $800 \mu \mathrm{g} \cdot \mathrm{day}^{-1}$, and 16 patients were treated with placebo. Medications required to control symptoms were inhaled $\beta$-agonists, which were used primarily on an asneeded basis. The treatment period was 4 weeks for each group. The study was carried out between July and October 1992. One patient in the active treatment group and four in the placebo group dropped out of the study due to an exacerbation of asthma during the period of study. The patients visited the clinic once during the selection period and, thereafter, every 2 weeks during the study. Before the start and the end of treatment, spirometry, and methacholine provocation test were performed and blood was collected for eosinophils. The best of three measurements of PEFR $\left(l \cdot \mathrm{min}^{-1}\right)$ were recorded daily by the patients using a Wright mini-peak flow meter (Airmed, London, UK), on awakening and before retiring, before fenoterol inhalation. The values of PEFR and the diurnal variability of PEFR (difference in the morning and evening values as a percentage of the mean) were averaged from the records on a diary card, 1 week before the start and the end of treatment. The number of inhalations of fenoterol $\left(200 \mu \mathrm{g} \cdot\right.$ puff $\left.^{-1}\right)$ taken as required was also recorded daily on diary cards.

\section{Methacholine bronchoprovocation}

Airway responsiveness to methacholine was determined by standard bronchial provocation techniques. Following measurement of baseline forced expiratory volume in one second $\left(\mathrm{FEV}_{1}\right)$ with a dry wedge spirometer (Vitalograph, Buckingham, UK), increasing concentrations of methacholine aerosol were delivered through a nebulizer attached to a French-Rosenthal dosimeter. Five breaths of aerosol were inhaled from the functional residual capacity position in the course of an inspiratory capacity manoeuvre. Methacholine concentrations $\left(0.075,0.15,0.3,0.6,1.25,2.5,5.0,10.0\right.$ and $\left.25.0 \mathrm{mg} \cdot \mathrm{ml}^{-1}\right)$ were prepared from a stock solution and diluted in buffered saline ( $\mathrm{pH}$ 7.4). Increasing concentrations of methacholine were given at 5 min intervals until the $\mathrm{FEV}_{1}$ fell by at least $20 \%$ compared to the value with the diluted (buffered saline) control. Spirometry was performed, and the best of three efforts for the FEV 1 was selected to construct a dose-response plot. The dose of methacholine required to produce a $20 \%$ decrease in $\mathrm{FEV}_{1}$ was calculated by linear interpolation according to an $\mathrm{FEV}_{1}$ versus $\log$ concentration of methacholine, and was defined as the 
$20 \%$ provocative concentration $\left(\mathrm{PC}_{20}\right)$. All patients received methacholine provocation tests in the morning from 9 to 11 a.m. following a cessation of medications for at least $12 \mathrm{~h}$.

\section{Preparation of multiple discontinuous density Percoll gradients for eosinophil separation}

Percoll (polyvinylpyrrolidone-coated silica gel; Pharmacia Fine Chemicals, Uppsala, Sweden) was mixed with 10× Hanks' balanced salt solution (HBSS) (JHR Biosciences, Lenexa, Kansas, USA) to make a stock solution with a density of $1.124 \mathrm{~g} \cdot \mathrm{ml}^{-1}$ and osmolality of $340 \pm 1$ mOsmol $\cdot \mathrm{kg}^{-1} \mathrm{H}_{2} \mathrm{O}$. Aliquots of the stock Percoll were then adjusted to densities of 1.080, 1.085, 1.090, 1.095 and $1.100 \mathrm{~g} \cdot \mathrm{ml}^{-1}$ by the addition of HBSS. Starting with the most dense solution, solutions of decreasing density were layered in a $16 \mathrm{ml}$ polycarbonated tube using a peristaltic pump at low speed. Gradients consisted of

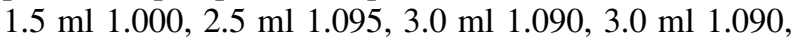
$3.0 \mathrm{ml} 1.085$, and $2.5 \mathrm{ml} 1.080 \mathrm{~g} \cdot \mathrm{ml}^{-1}$ Percoll. Before fractionation, Density Marker Beads (Pharmacia Fine Chemicals AB, Uppsala, Sweden) were used as an external marker for calibration of gradients of Percoll. The Density Marker Beads were prepared following the instructions of the manufactures.

\section{Preparation of granulocyte suspension}

Twenty millilitres of venous blood from asthmatics, and $60 \mathrm{ml}$ from normal subjects, obtained before each methacholine bronchoprovocation test, were anticoagulated with heparin (10 units. $\mathrm{ml}^{-1}$ blood $)$, and sedimented with $6 \%$ dextran (5 volumes of blood: 1 volume of dextran) for $1 \mathrm{~h}$ at $37^{\circ} \mathrm{C}$. The leucocyte-rich supernatant was then fractionated on Ficoll-Hypaque density gradients. After centrifugation $(750 \times \mathrm{g}$ for $20 \mathrm{~min})$, the mononuclear cell band was removed and the granulocyte pellet was washed twice in $\mathrm{Ca}^{2+}$ - free, $\mathrm{Mg}^{2+}$ - free HBSS and resuspended at a concentration of $20 \times 10^{6}$ or $50 \times 10^{6}$ cells $\cdot \mathrm{ml}^{-1}$ in HBSS containing $5 \%$ foetal calf serum in asthmatic patients or normal subjects, respectively. Very few eosinophils $(2.9 \pm 0.5 \%$ of total eosinophils; $n=12)$ were retained in the mononuclear cell layer, indicating that very hypodense eosinophils constitute only a small portion of total eosinophils. In addition, the drawn blood samples from asthmatics were submitted to our central laboratory to determine absolute eosinophil counts.

\section{Separation of eosinophils and neutrophils by Percoll density gradient centrifugation}

A $2 \mathrm{ml}$ aliquot of the granulocyte suspension was carefully layered onto the multidiscontinuous density Percoll gradient, and then centrifuged at $700 \times \mathrm{g}$ for 20 min at $20^{\circ} \mathrm{C}$. After centrifugation, cells were gently aspirated from each of the density gradient interfaces. The cells from each band were counted and the purity of eosinophils was determined by examination of 200 cells on a Giemsa-Wright stained cytocentrifuge preparation. To avoid observer's bias during counting, the samples were coded and counted by a senior technician who was unaware of the study. From these data, the fraction (percentage) of total eosinophils recovered from each gradient interface was determined. The recovery of eosinophils from gradients was $90 \pm 1 \%(\mathrm{n}=27)$ for the asthma group and $88 \pm 4 \%(n=7)$ for the normal group. There was no significant difference in eosinophil recovery between the two groups.

The acceptability of variability in measuring the percentage of hypodense eosinophils was determined using the methods of BLAND and ALTMAN [18], whereby duplicate measurements are made and the difference between the two is calculated. If $95 \%$ of the differences are within two standard deviations (SD) of the mean differences, variability is considered to be acceptable. Thus, variation was determined by duplicate measurements of the percentage of hypodense eosinophils for each of 22 patients (17 asthma patients and 5 normal subjects). The mean difference after duplicate measurements of the percentage of hypodense fraction was $4.5 \pm 8.4 \%$ (mean $\pm \mathrm{sD} ; \mathrm{n}=22$ ) which was not significantly different from 0 . Twenty one out of 22 differences $(>95 \%)$ were within 2 SD of the mean difference, which demonstrated that the variability in determination of the percentage of hypodense fraction within acceptable limits.

To determine whether Percoll separation may activate eosinophils, superoxide (SO) anion release was measured [19] in granulocytes fractionated on Ficoll-Hypaque density gradient from five patients ( 3 asthmatics and 2 normal subjects with a mean percentage of eosinophil $7.3 \pm 2.5 \%$ ). Briefly, $10^{6}$ granulocytes resuspended in HBSS or Percoll solution at densities of 1.070, 1.090 and $1.100 \mathrm{~g} \cdot \mathrm{ml}^{-1}$ were placed in wells of a 96-well plate with $1.2 \mathrm{mg} \cdot \mathrm{ml}^{-1}$ ferricytochrome c, $0.1 \%$ gelatin, with or without $25 \mathrm{ug} \cdot \mathrm{ml}^{-1}$ superoxide dismutase, in a final volume of $20 \mu \mathrm{l}$ of HBSS of Percoll solution. Spontaneous function was measured without activator. Optical density at $550 \mathrm{~nm}$ was determined using a Titertek Multiscan spectrophotometer (MCC/340; Flow Laboratories). Measurement was made initially and at 30 and $60 \mathrm{~min}$, and each optical density was converted to nanomoles of SO anion, using a molar extinction coefficient of 21.1 $\mathrm{mM}^{-1} \mathrm{~cm}^{-1}$. Data at $60 \mathrm{~min}$ are reported here and were expressed as nanomoles SO anion released per $10^{6}$ cells per hour. Granulocytes incubated in Percoll solution at densities of $1.070,1.090$ and $1.100 \mathrm{~g} \cdot \mathrm{ml}^{-1}$ did not release significantly more superoxide anion $(0.64 \pm 0.3,0.6 \pm 0.1$ and $0.7 \pm 0.2 \mathrm{~nm} \cdot 10^{-6}$ cells respectively; $\left.\mathrm{n}=5\right)$, than cells incubated in HBSS $\left(0.8 \pm 0.3 \mathrm{~nm} \cdot 10^{-6}\right.$ cells; $\left.\mathrm{n}=5 ; \mathrm{p}>0.05\right)$, indicating that cells were not activated during Percoll separation.

\section{Eosinophil cationic protein (ECP) measurements}

ECP measurements in the serum were performed using a double antibody radio-immunoassay (Pharmacia Diagnostics AB, Uppsala, Sweden). The assay is based on the competition of radiolabelled ECP for the binding sites of a specific monoclonal antibody. Calibration is realized 
against pure ECP. The detection limit is $<2 \mu \mathrm{g} \cdot l^{-1}$. The procedure was performed following the instructions of the manufacturers. The coefficient of variation of ECP measurement was $6.3 \%$ determined on six samples, each of which was in three replicates, and measured on 18 occasions.

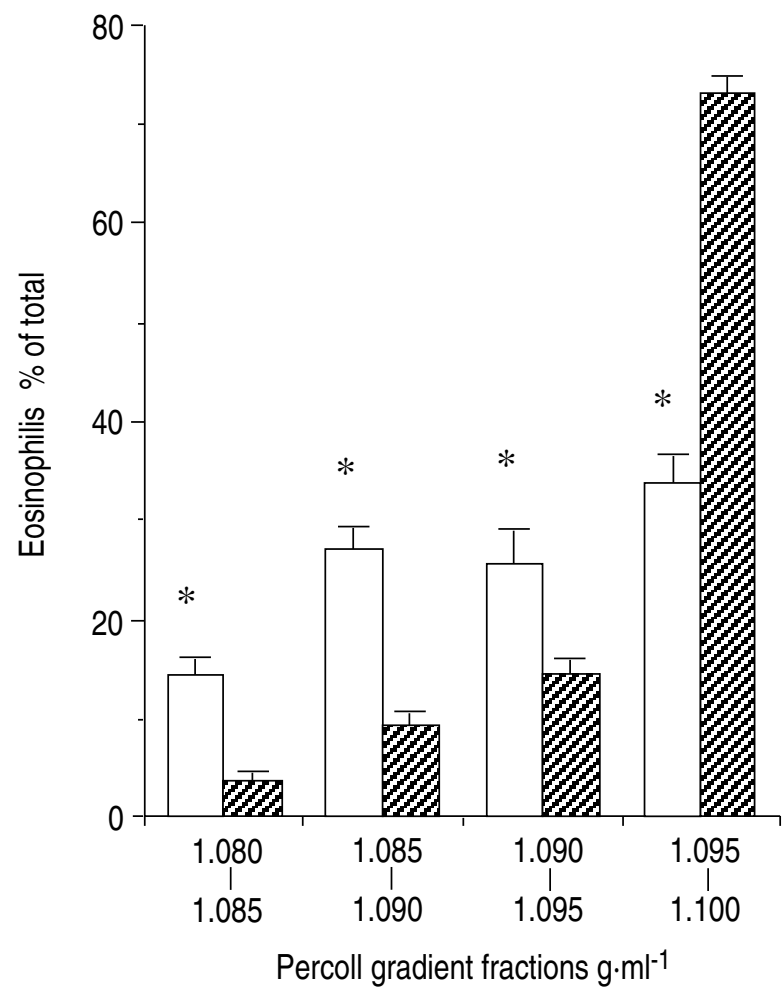

Fig. 1. - Distribution profiles of blood eosinophils of normal subjects ( $\circlearrowright$; n=7) and patients with asthma $(\square ; n=27)$ in the different Percoll gradient fractions. Values are mean \pm sEM. ${ }^{*}: \mathrm{p}<0.01$ compared with corresponding fraction in normal subjects.

\section{Statistical analysis}

The data are expressed as mean \pm SEM. Statistical analysis of results was performed by Student's t-test for paired data, or one way analysis of variance followed by Bonferroni corrected t-test, when multiple comparisons were made. For data with uneven variation, a Mann-Whitney U-test was used. Correlation of data was sought by Spearman's rank correlation test. A p-value of $<0.05$ was considered significant.

\section{Results}

Patients with asthma had a higher absolute eosinophil count $\left(584.1 \pm 69.2\right.$ counts $\left.\cdot \mathrm{mm}^{-3} ; \mathrm{n}=27 ; \mathrm{p}<0.01\right)$ in the peripheral blood than normal subjects $(85.1 \pm 65.2$ counts $\left.\cdot \mathrm{mm}^{-3} ; \mathrm{n}=7\right)$. The relative cell counts of eosinophil shifted to the lower density ranges in asthmatics compared with normal subjects (fig. 1). The majority of eosinophils in normal subjects were concentrated in the density ranging from $1.095-1.100 \mathrm{~g} \cdot \mathrm{ml}^{-1}(73 \pm 2 \% ; \mathrm{n}=7)$ compared with those of asthmatics $(37 \pm 3 \% ; \mathrm{n}=27 ; \mathrm{p}<0.001)$. In contrast, the majority of eosinophils in asthmatics were recovered in the density $<1.095 \mathrm{~g} \cdot \mathrm{ml}^{-1}$, and were then termed as hypodense eosinophils (fig. 1). The proportion of hypodense eosinophils in asthmatics $(63 \pm 3 \% ; n=27)$ was higher than that of normal subjects $(27 \pm 2 \% ; n=7$; $\mathrm{p}<0.001$ ).

Fifteen patients in the active treatment group and 12 patients in the placebo group completed the study and their characteristics are presented in table 1. There were no significant differences between patients in the active treatment group and those in the placebo group in terms of age, sex, baseline spirometry, PEFR, methacholine $\mathrm{PC}_{20}$, absolute eosinophil counts and hypodense eosinophil percentage (table 1).

Table 1. - Characteristics of patients and the effect of 4 week budesonide on pulmonary function and peripheral blood eosinophils

\begin{tabular}{|c|c|c|c|c|}
\hline \multirow{4}{*}{$\begin{array}{l}\text { Age yrs } \\
\text { Sex } \mathrm{M} / \mathrm{F}\end{array}$} & \multicolumn{2}{|c|}{$\begin{array}{c}\text { Budesonide } \\
\quad(\mathrm{n}=15)\end{array}$} & \multicolumn{2}{|c|}{$\begin{array}{c}\text { Placebo } \\
(n=12)\end{array}$} \\
\hline & \multirow{2}{*}{\multicolumn{2}{|c|}{$\begin{array}{c}37 \pm 4 \\
7 / 8\end{array}$}} & \multirow{2}{*}{\multicolumn{2}{|c|}{$\begin{array}{c}38 \pm 4 \\
6 / 6\end{array}$}} \\
\hline & & & & \\
\hline & Before & After & Before & After \\
\hline $\mathrm{FEV}_{1} \%$ pred & $70 \pm 5$ & $87 \pm 5^{* *}$ & $82 \pm 8$ & $89 \pm 7$ \\
\hline $\mathrm{PC}_{20} \mathrm{mg} \cdot \mathrm{ml}^{-1}$ & $5.7 \pm 3.8$ & $11.1 \pm 5.9 * *$ & $5.1 \pm 3.1$ & $4.1 \pm 2.6$ \\
\hline PEFR $l \cdot \mathrm{min}^{-1}$ & $373 \pm 29.7$ & $429 \pm 22.9 * *$ & $399 \pm 27.6$ & $368 \pm 28.9$ \\
\hline$\triangle \mathrm{PEFR} \% \S$ & $12.9 \pm 1.9$ & $7.5 \pm 1.2 * *$ & $7.4 \pm 1.3$ & $9.9 \pm 2.6$ \\
\hline $\begin{array}{l}\text { Use of fenoterol } \\
\text { puffs.week }{ }^{-1}\end{array}$ & $18.6 \pm 0.8$ & $7.6 \pm 0.4 * *$ & $17.6 \pm 0.7$ & $19.0 \pm 1.0$ \\
\hline AEC counts $\cdot \mathrm{mm}^{-3}$ & $621 \pm 136$ & $174 \pm 52 *$ & $547 \pm 141$ & $436 \pm 83$ \\
\hline $\begin{array}{l}\text { Hypodense } \\
\text { eosinophils \% }\end{array}$ & $68 \pm 4$ & $47 \pm 4 * * *$ & $63 \pm 4$ & $65 \pm 4$ \\
\hline
\end{tabular}

Values are mean \pm SEM. $\$:$ the variability of PEFR; *,**,***: $\mathrm{p}<0.05,0.01,0.001$ compared with before treatment. M: male; F: female; $\mathrm{FEV}_{1}$ : forced expiratory volume in one second; $\mathrm{PC}_{20}$ : provocative concentration of methacholine producing a $20 \%$ fall in $\mathrm{FEV}_{1}$; PEFR: peak expiratory flow rate; AEC: absolute eosinophil count. 


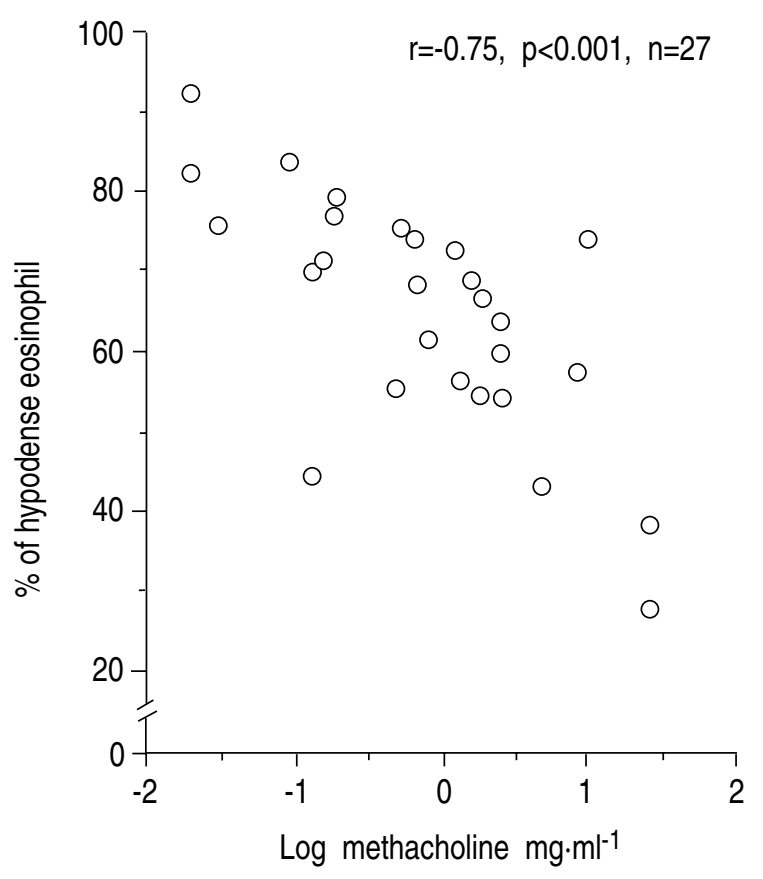

Fig. 2. - Correlation between the percentage of hypodense eosinophils and methacholine $\mathrm{PC}_{20}$ in patients with asthma $(\mathrm{n}=27)$. A significant correlation is indicated. $\mathrm{PC}_{20}$ : provocative concentration producing a $20 \%$ fall in forced expiratory volume in one second.

The methacholine $\mathrm{PC}_{20}$ value was inversely related to the percentage of hypodense eosinophil $(\mathrm{r}=-0.75 ; \mathrm{n}=0.27$; $\mathrm{p}<0.001$ ) (fig. 2), and also to the absolute eosinophil counts $(\mathrm{r}=-0.51 ; \mathrm{n}=27 ; \mathrm{p}<0.05)$ within the asthma group. The severity of asthma was found to be related to the percentage of hypodense eosinophils. Patients with mild asthma had a lower percentage of hypodense eosinophils $(45 \pm 4 \% ; n=14)$ than those with moderate asthma $(67 \pm 3 \%$; $\mathrm{n}=13$; $\mathrm{p}<0.01$ ) (fig. 3). The proportion of hypodense

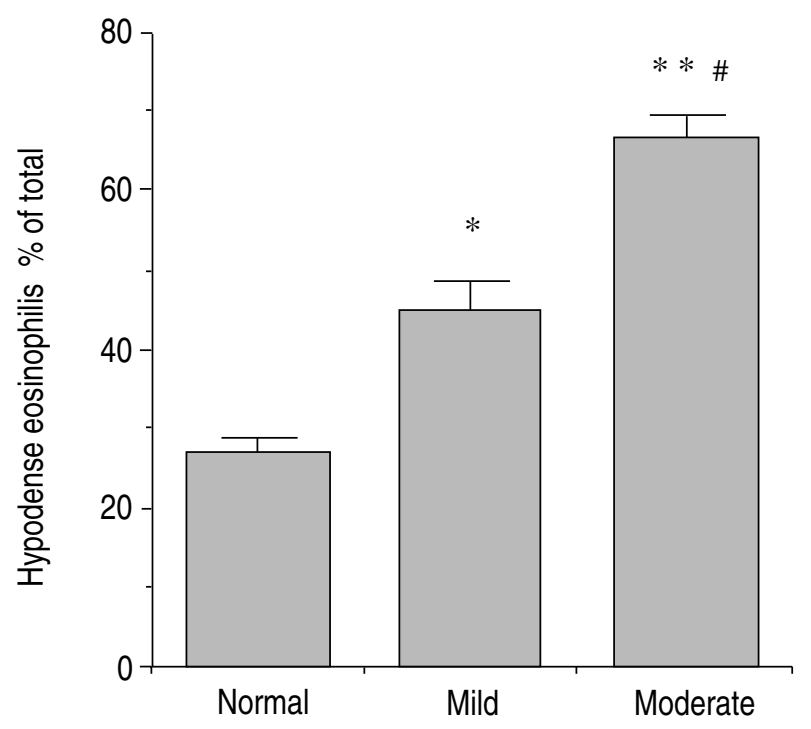

Fig. 3. - Percentage of blood hypodense eosinophils in normal subjects and patients with mild $(n=14)$ and moderate asthma $(n=13)$. Values are mean $\pm \operatorname{SEM}(\mathrm{n}=7)$. *: $\mathrm{p}<0.05 ; * *: \mathrm{p}<0.01$ compared with normal subjects; \#: $\mathrm{p}<0.01$ compared with mild asthmatics. eosinophils were not significantly related to the absolute eosinophil counts in patients with asthma $(\mathrm{r}=0.38$; $\mathrm{p}>0.05 ; \mathrm{n}=27$ ).

Inhalation of budesonide induced a significant increase in the methacholine $\mathrm{PC}_{20}$ values but not placebo treatment (table 1). Budesonide significantly $(\mathrm{p}<0.01 ; \mathrm{n}=15)$ increased the values of $\mathrm{FEV}_{1} \%$ by $17 \pm 4 \%$ and PEFR from $373 \pm 29.7$ to $429 \pm 22.9 \mathrm{l} \cdot \mathrm{min}^{-1}$, and decreased the variability of PEFR from $12.9 \pm 1.9$ to $7.5 \pm 1.2 \%$ (table 1). In contrast, placebo treatment failed to significantly
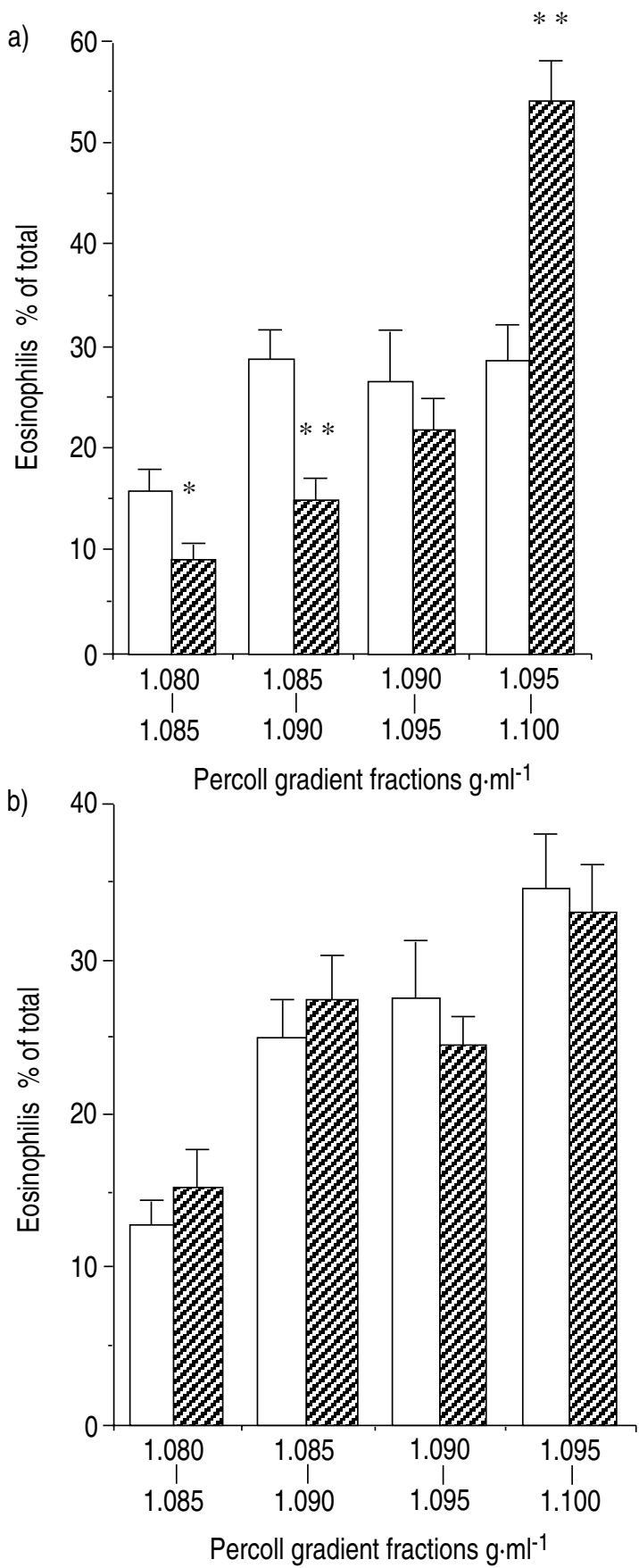

Fig. 4. - The distribution profiles of blood eosinophils in the different Percoll gradient factors in patients with asthma before ( $\square$ ) and after ( $(\mathbb{A})$ treatment with: a) budesonide $(\mathrm{n}=15)$; or b) placebo $(\mathrm{n}=12)$. Values are mean \pm SEM. **: $\mathrm{p}<0.01 ; *$ : $\mathrm{p}<0.05$ compared with corresponding fraction before treatment. 
improved $\mathrm{FEV}_{1}$, PEFR or the variability of PEFR (table 1). There was a significant decrease in the number of blood eosinophils and the percentage of hypodense eosinophils in the budesonide treatment group but not in the placebo group (table 1). Budesonide, but not placebo treatment, also caused a significant change in the distribution profiles of eosinophil subpopulation (fig. 4). The proportions of eosinophils in the lower densities (1.080-1.085 and $\left.1.085-1.090 \mathrm{~g} \cdot \mathrm{ml}^{-1}\right)$ significantly $(\mathrm{p}<0.01)$ decreased, with a concomitant significant increase in the highest density (1.095-1.100 g. $\mathrm{ml}^{-1}$ ) after budesonide treatment.

The serum ECP level in patients after budesonide treatment was $12.1 \pm 0.8 \mu \mathrm{g} \cdot \mathrm{ml}^{-1}(\mathrm{n}=15)$, which was significantly higher than that of normal subjects $(5.7 \pm 0.5$ $\left.\mu \mathrm{g} \cdot \mathrm{ml}^{-1} ; \mathrm{n}=7 ; \mathrm{p}<0.01\right)$, but much lower than patients with placebo treatment $\left(36.4 \pm 11.1 \mu \mathrm{g} \cdot \mathrm{ml}^{-1} ; \mathrm{n}=12 ; \mathrm{p}<0.001\right)$. Although the ECP level in asthmatic patients with a higher proportion of hypodense eosinophils $(>50 \%)$ $\left(47.3 \pm 6.8 \mu \mathrm{g} \cdot \mathrm{ml}^{-1} ; \mathrm{n}=18\right)$ was significantly higher than that in patients with a lower proportion of hypodense eosinophils $(<50 \%)\left(23.1 \pm 3.7 \mu \mathrm{g} \cdot \mathrm{ml}^{-1} ; \mathrm{n}=9 ; \mathrm{p}<0.02\right)$, there was no significant correlation between the proportions of hypodense eosinophils and serum ECP level ( $\mathrm{r}=0.11$; $\mathrm{n}=27 ; \mathrm{p}>0.05$ ). The proportion of remaining hypodense eosinophils in patients after budesonide treatment was not significantly correlated with methacholine $\mathrm{PC}_{20}(\mathrm{r}=$ $-0.05 ; \mathrm{p}>0.1)$.

\section{Discussion}

In the present study, we demonstrated that hypodense eosinophils were significantly increased in patients with asthma, and that the proportions of hypodense eosinophils were closely related to the asthma severity and airway hyperresponsiveness. Four week inhaled budesonide treatment significantly decreased the proportions of hypodense eosinphils, with a concomitant improvement in $\mathrm{FEV}_{1}, \mathrm{PEFR}, \mathrm{PEFR}$ variability and methacholine $\mathrm{PC}_{20}$. The distribution profiles of eosinophil subpopulations also shifted toward normodense gradients after treatment with budesonide.

Eosinophils were fractionated by centrifugation through a discontinuous gradient of Isosmotic Percoll. In the present study, the spontaneous oxidative metabolism (an early event of cell activation after membrane triggering) in granulocytes incubated in three different density Percoll solutions was not significantly different from cells incubated in HBSS, indicating that Percoll solutions did not appear to affect the cell activation, which was consistent with the report by DAUBER et al. [20].

The connection between asthma and the eosinophil granulocyte seems fundamental, and is present irrespective of an allergic component of the disease [21]. The close relationship between peripheral total eosinophil counts and the severity of asthma was documented in a previous study [5], and also in the present study. Hypodense eosinophils are characteristic of an increased number of receptors for immunoglobulin and complement, as well as an increased response to chemotaxis, and increased metabolic activity. The changes result in increased secretory activity and increased killing capacity $[9,10$, 22]. Therefore, the increase in the proportion of hypodense eosinophils in asthmatics in the present study indicates an in vivo activation of eosinophils.

Eosinophils contain an abundance of heavily basic, medium-sized proteins in their secretory granules, including ECP, eosinophilic protein X (EPX), major basic proteins (MBP) and active mediators, such as platelet activating factors (PAF) and leukotrienes [22]. MBP and ECP have been demonstrated to damage the surface epithelium of the airway, from detachment of the superficial part of the epithelium to a total removal of the surface epithelium [23]. Investigations have revealed a clear correlation between ECP level and cellular injury in the lung tissue from severe asthma [24]. These cytotoxic effects, in conjunction with vascular permeability to plasma proteins and chemotaxis for inflammatory cells induced by PAF and leukotrienes $[25,26]$ released from eosinophils, have been considered to be the underlying mechanism responsible for airway hyperresponsiveness [27]. The density distribution of eosinophils has been shown to be related to the ECP content [28], and plasma MBP level [11]. Thus, the different stages of eosinophil activation through release of cytotoxic proteins and mediators may be related to the development of airway hyperresponsiveness. Our results, showing a highly significant correlation between the proportions of hypodense eosinophil and methacholine $\mathrm{PC}_{20}$, support this hypothesis.

In this study, treatment with inhaled budesonide caused a significant decrease in the percentage of hypodense eosinophils with a concomitant increase in methacholine $\mathrm{PC}_{20}$, further indicating a close relationship between hypodense eosinophils and airway hyperresponsiveness. However, despite these changes, bronchial hyperresponsiveness was still apparent in most of our patients during the treatment, and there was no relationship between $\mathrm{PC}_{20}$ and the proportion of remaining hypodense eosinophils after budesonide treatment, indicating that the development of airway hyperresponsiveness in not totally attributed to an activation of eosinophils. The effect of corticosteroids on airway hyperresponsiveness may be partly mediated via an inhibition of other mediators involved in the pathogenesis of airway inflammation but not in eosinophil activation.

A significantly higher percentage of hypodense eosinophils in patients with moderate asthma than in patients with mild asthma suggested that the extent of eosinophil activation was related to the clinical severity. Whether the increase in hypodense eosinophils directly contributes to the development of airway hyperresponsiveness as well as clinical manifestations, or whether this increase arises secondary to other processes involved in airway inflammation, cannot be determined from the present results.

A number of mechanisms have been demonstrated to participate in the development of low density eosinophils. The complex processes causing activation of eosinophils involve several proinflammatory mediators, including platelet-activating factor and leukotriene $\mathrm{B}_{4}\left(\mathrm{LTB}_{4}\right)$ from mast cells or basophils [29, 30], eosinophil cytotoxicityenhancing factor (ECEF) and eosinophil-activating factor 
from macrophages [31], as well as lymphokines from Tlymphocytes [32]. Among those mediators, $\mathrm{LTB}_{4}$ and platelet-activating factor (PAF) can enhance leucocyte metabolic activity [29, 33], and cause cell density to decrease [34]. Intravenous infusion of interleukin-2 (IL2) in human subjects increases the appearance of peripheral blood hypodense eosinophils [35]. IL-2 further releases other cytokines, such as granulocytes/macrophage colony-stimulating factor (GM-CSF) [36], interleukin-5 (IL-5) [37], and interleukin-3 (IL-3) [38] to decrease eosinophil density. Therefore, the inhibitory response to inhaled budesonide in this study was probably through an inhibition of the release of cytokines (e.g. IL3 , GM-CSF) and other mediators, such as PAF, acting on the conversion to hypodense phenotype. However, it is also possible that glucocorticoids exert a direct effect on eosinophils themselves, as shown previously in vitro [39].

In this study, the decrease in the proportion of hypodense eosinophils was accompanied by a concomitant change in the total number of circulating eosinophils, suggesting that it is possible that the hypodense eosinophil represents a relatively immature cell released early from the bone marrow, and its appearance may be related more to the number of peripheral blood eosinophils than their activation status. Therefore, the response of hypodense eosinophils to corticosteroids is merely due to a decrease in total eosinophil counts. However, the correlation between the proportions of hypodense eosinophils and circulating total eosinophil counts in asthmatics was weak, which was consistent with a previous report [11]. Furthermore, the distribution profiles of eosinophils also shifted to a predominance of normodense eosinophils after corticosteroid treatment, suggesting that corticosteroids influenced the eosinophil activation rather than simply decreased the cell numbers of eosinophils. The serum level of ECP in patients after corticosteroid treatment was significantly higher than that of normal subjects, but much lower than that of patients with placebo treatment, suggesting that most of the eosinophil activation has been suppressed.

The confounding effect of altering exposure to allergens may influence the magnitude of hypodense eosinophils during the course of study. However, it seems unlikely for two reasons. Firstly, the study was carried out in the period between July and October; in this period there were no significant changes in allergen exposure leading to a seasonal asthma, due to the Oceanic climate in Taiwan. Secondly, patient populations in the placebo group seemed to be no different from those in the active treatment group. However, there was no significant change in the eosinophil subpopulations or total eosinophil counts in the placebo group during the course of the study.

In addition to glucocorticoids, the other maintenance medications, $\beta$-agonists, may decrease the number of circulating eosinophils and the serum level of ECP [40]. In this study, patients in the placebo group required more fenoterol use to relieve symptoms that those in steroid treatment group. However, there was no significant change in either eosinophil number or the proportions of hypodense eosinophils in the placebo group, indicating that the effect of concomitant $\beta$-agonists was not significant.

Our results confirmed the effect of corticosteroid on eosinophil subpopulation distribution recently reported by Evans et al. [41]. This study further explored a close relationship between hypodense eosinophils and airway hyperresponsiveness as well as clinical severity. The concomitant improvement in clinical severity and airway hyperresponsiveness after steroid treatment, with a decrease in the portion of hypodense eosinophils, further supports such a close relationship.

In conclusion, in this study, we found a close relationship between hypodense eosinophils and airway hyperresponsiveness, as well as clinical severity, in patients with asthma. The topical corticosteroid, budesonide, had a marked suppressive action on the proportion of hypodense eosinophils in the peripheral blood. Inhaled budesonide also shifted the distribution profiles to a prominence of normodense eosinophils similar to that in normal subjects. Because these cellular changes were paralleled by the changes in the indices of clinical activities, we suggest that they are relevant to the therapeutic efficacy of this class of drugs in asthma. However, it is not clear whether the airway eosinophils also possess a similar phenomenon and a corresponding response to corticosteroids. A future study with concurrent measurements of eosinophil subpopulations and ECP level in the blood and bronchoalveolar lavage fluid in patients with asthma may further advance our understanding of the role of hypodense eosinophils in asthma.

\section{References}

1. Beasley R, Roche WR, Roberts JA, Holgate ST. Cellular events in the bronchi in mild asthma and after bronchial provocation. Am Rev Respir Dis 1989; 139: 806817.

2. Gleich GJ. The eosinophil and bronchial asthma: current understanding. J Allergy Clin Immunol 1990; 85: 422436.

3. Fredens K, Dahl R, Venge P. The Gordon phenomenon induced by eosinophil cationic protein and eosinophil protein X. J Allergy Clin Immunol 1982; 70: 361366.

4. Barnes PJ, Chung KF, Page CP. Inflammatory mediators and asthma. Pharmacol Rev 1988; 40: 49-84.

5. Frick WE, Sedgwick JB, Busse WW. The appearance of hypodense eosinophils in antigen-dependent late-phase asthma. Am Rev Respir Dis 1989; 139: 1401-1406.

6. Wardlaw AJ, Dunnette S, Gleich GJ, Collins JV, Kay AB. Eosinophils and mast cells in bronchoalveolar lavage in subjects with mild asthma. Am Rev Respir Dis 1980; 122: 709-719.

7. Venge P, Hakansson L, Peterson CGB. Eosinophil activation in allergic disease. Int Arch Allergy Appl Immunol 1987; 137: 62-69.

8. Bousquet J, Chanez, P, Lacoste JY, et al. Eosinophilic inflammation in asthma. $N$ Engl J Med 1990; 323: 1033-1039.

9. Winqvist I, Olofsson I, Persson A, Hallberg T. Altered density, metabolism and surface receptors in eosinophilia. Immunology 1982; 47: 531-539. 
10. Prin L, Capron M, Tonnel AB, Bletry O, Capron A. Heterogeneity of human peripheral blood eosinophils: variability in cell density and cytotoxic ability in relation to the level and the origin of hypereosinophilia. Int Arch Allergy Appl Immunol 1983; 72: 336-346.

11. Fukuda T, Dunnette SL, Reed CE, Ackerman SJ, Peters MS, Gleich GJ. Increased numbers of hypodense eosinophils in the blood of patients with bronchial asthma. Am Rev Respir Dis 1985; 132: 981-985.

12. Calhoun WJ, Bates ME, Schrader L, Sedgwick JB, Busse WW. Characteristics of peripheral blood eosinophils in patients with nocturnal asthma. Am Rev Respir Dis 1992; 145: 577-581.

13. Djukanovic R, Wilson JW, Britten KM, et al. Effect of an inhaled corticosteroid on airway inflammation and symptoms in asthma. Am Rev Respir Dis 1992; 145: 669-674.

14. Dutoit JI, Salome CM, Woolcock AJ. Inhaled corticosteroids reduce the severity of bronchial hyperresponsiveness in asthma but oral theophylline does not. Am Rev Respir Dis 1987; 136: 1174-1178.

15. Kraan J, Koeter GH, Mark TW, et al. Dosage and time effects of inhaled budesonide on bronchial hyperreactivity. Am Rev Respir Dis 1988; 137: 44-48.

16. Chronic bronchitis, asthma and pulmonary emphysema: a statement by the Committee on Diagnostic Standards for Nontuberculous Respiratory Diseases. Am Rev Respir Dis 1962; 85: 762-768.

17. Kay $\mathrm{AB}$, Holgate ST. International consensus report on the diagnosis and management of asthma. Clin Exp Allergy 1992; 22 (Suppl. 1): 1-5.

18. Bland JM, Altman DG. Statistical methods for assessing agreement between two methods of clinical measurements. Lancet 1986; i: 307-310.

19. Shult PA, Graziano FM, Wallo IH, Busse WW. Comparison of superoxide production and luminol-enhanced chemiluminescence with eosinophils and neutrophils from normal individuals. J Lab Clin Med 1985; 106: 638645.

20. Dauber JH, Holian A, Rosemiller ME, Danielle RP. Separation of bronchoalveolar cells from the guinea-pig on continuous density gradients of Percoll: morphology and cytochemical properties of fractionated lung macrophages. J Reticuloendothel Soc 1983; 33: 119-126.

21. Taylor KJ, Luksza AR. Peripheral blood eosinophil counts and bronchial responsiveness. Thorax 1987; 42: 452-456.

22. Kajita T, Yui Y, Mita H, et al. Release of leukotriene $\mathrm{C}_{4}$ from human eosinophils and its relation to the cell density. Int Arch Allergy Appl Immunol 1985; 78: 406-410.

23. Gleich GJ, Flavahan NA, Fujisawa T, Vanhoutte PM. The eosinophil as a mediator of damage to respiratory epithelium: a model for bronchial hyperreactivity. $J$ Allergy Clin Immunol 1988; 81: 776-781.

24. Fredens K, Dybdahi H, Dahl R, Baandrup V. Extracellular deposit of the cationic proteins ECP and EPX in tissue infiltrations of eosinophils related to tissue damage. APMIS 1988; 96: 711-719.

25. Lee T-C, Lenihan DJ, Malone B, Roddy LL, Wasserman SI. Increased biosynthesis of platelet-activating factor in activated human eosinophils. J Biol Chem 1984; 259: 5526-5530.

26. Shaw RJ, Cromwell O, Kay AB. Preferential genera- tion of leukotriene $\mathrm{C}_{4}$ by human eosinophil. Clin Exp Immunol 1984; 70: 716-722.

27. Chung KF. Role of inflammation in the hyperreactivity of the airways in asthma. Thorax 1986; 41: 657-662.

28. Olsson I, Venge P, Spitznagel JK, Lehrer RJ. Argininerich cationic proteins of human eosinophil granules. Comparison of the constituents of eosinophilic and neutrophilic leukocytes. Lab Invest 1977; 36: 493.

29. Peters SP, Freeland HS, Kelly SJ, et al. Is leukotriene $\mathrm{B}_{4}$ an important mediator in human IgE-mediated allergic reactions? Am Rev Respir Dis 1987; 135: S42.

30. Camussi G, Aglietta M, Coda R, Bussolino F, Pracibella W, Tetta C. Release of platelet-activating factor (PAF) and histamine. II. The cellular origin of human PAF: monocytes, polymorphonuclear neutrophils and basophils. Immunol 1981; 42: 191-197.

31. Joseph M, Tonnel AB, Capron A, Dessaint JP. The interaction of IgE antibody with human alveolar macrophages and its participation in the inflammatory processes in the lung. Agents Actions 1981; 11: 619-622.

32. Berman JS, Weller PF. Airway eosinophils and lymphocytes in asthma. Am Rev Respir Dis 1992; 145: 12461248.

33. Bruynzeel PLB, Koenderman L, Kok PTM, Hameling ML, Verhagen J. Platelet activating factor (PAF-acether) induced leukotriene $\mathrm{C}_{4}$ formation and luminal dependent chemiluminescence by human eosinophils. Pharmacol Res Commun 1986; 18: 61-69.

34. Yukawa T, Kroegel C, Evans P, Fukuda T, Chung KF, Barnes PJ. Density heterogeneity of eosinophil leukocytes: induction of hypodense eosinophils by plateletactivating factor. Immunology 1989; 68: 140-143.

35. Sedgwick JB, Frick WE, Busse WW. The appearance of hypodense eosinophils (HE) during interleukin-2 (IL-2) treatment. J Allergy Clin Immunol 1988; 81: 208.

36. Own WF, Rothenberg ME, Silberstein DF, et al. Regulation of human eosinophil viability, density, and function by granulocyte/macrophage colony-stimulating factor in the presence of 3 T3 fibroblasts. J Exp Med 1987; 166: 129-146.

37. Rothenberg ME, Petersen J, Stevens RL, et al. IL-5dependent conversion of normodense human eosinophils to the hypodense phenotype uses $3 \mathrm{~T} 3$ fibroblasts for enhanced viability, accelerated hypodensity and sustained antibody-dependent cytotoxicity. J Immunol 1989; 143: 2311-2316.

38. Rothenberg ME, Owen WF, Silberstein DS, et al. Human eosinophils have prolonged survival, enhanced functional properties, and become hypodense when exposed to human interleukin-3. J Clin Invest 1988; 81: 1986-1992.

39. Lamas AM, Leon OG, Schleimer RP. Glucocorticoids inhibit eosinophil responses to granulocyte macrophage colony-stimulating factor. J Immunol 1991; 147: 254259.

40. Ohman JL, Lawrence M, Lowell FC. Effect of propranolol on the eosinophil responses of cortisol, isoproterenol and aminophylline. J Allergy Clin Immunol 1972; 50: 151-156.

41. Evans PM, O'Connor BJ, Fuller RW, Barnes PJ, Chung KF. Effect of inhaled corticosteroids on peripheral blood eosinophil counts and density profiles. J Allergy Clin Immunol 1993; 91: 643-650. 